\title{
Farklı Azot Dozlarının Bermuda Çimi (Cynodon sp.)’nin Gelişimi ve Çim Kalitesi Üzerine Etkileri
}

\author{
Uğur BİLGİLI $\dot{I}^{1} \quad$ Sinem ZERE Z $^{1} \quad$ Fikret YÖNTER ${ }^{1}$ \\ ${ }^{1}$ Uludağ Üniversitesi Ziraat Fakültesi Tarla Bitkileri Bölümü \\ $\triangle$ : ubilgili@uludag.edu.tr
}

Geliş (Received): 02.11.2017

Kabul (Accepted): 15.12.2017

\begin{abstract}
ÖZET: Bu çalışma, 2015-2016 yıllarında, Uludağ Üniversitesi, Ziraat Fakültesi Tarımsal Uygulama ve Araştırma Merkezi'ndeki Çim Deneme Alanı'nda, Bermuda çimine uygulanan farklı azot dozlarının bitki gelişimi ve çim kalitesi üzerine etkilerini araştırmak amacıyla tesadüf blokları deneme deseninde bölünmüş parsellere göre 3 tekrarlamalı olarak yürütülmüştür. Ana parsellere çim türleri, alt parsellere ise azot dozları yerleştirilmiştir. Ana parsellerde kullanılan bitki materyalleri; melez Bermuda çimi (Cynodon dactylon x Cynodon transvaalensis)'nin Tifdwarf, yaygın Bermuda çimi (Cynodon dactylon L. Pers.)'nin Gobi ve Sydney çeşitleridir. Alt parsellerde yer alan; 0, 2, 4 ve $6 \mathrm{~g} / \mathrm{m} 2$ azot dozları ise 7 ay süresince uygulanmıştır. Çim renk ve kalite değerleri aylık olarak, kuru ot verimleri ise bitkiler $8-10 \mathrm{~cm}$ boya eriştiklerinde alt parsellerden alınmış, ayrıca dormansi tarihleri belirlenmiştir. İki yıllık araştırma sonuçlarına göre artan azot dozları; çim renk ve kalitesi ile kuru ot verimlerini artırmıştır. $4 \mathrm{~g} / \mathrm{m} 2$ azot dozu uygulamasının üç çim çeşidinde kabul edilebilir çim renk ve kalite değerleri verdiği gözlenmiştir. Tifdwarf ve Gobi çeşitlerinin dormansiden ilk çıkan çeşitler olduğu tespit edilmiştir.

Anahtar Kelimeler: Azot, Sıcak İklim Çim Bitkileri, Bermuda Çimi, Tifdwarf, Gobi, Sydney
\end{abstract}

\section{Effects of Different Nitrogen Rates on Plant Growing and Turf Quality of Bermudagrass (Cynodon sp.)}

\begin{abstract}
Field experiments will be carried out on turf research plots at Uludag University Research Farm, Bursa $\left(40^{\circ} 11^{\prime} \mathrm{N}, 2^{\circ} 04^{\prime} \mathrm{E}\right)$, between $2015-2016$ years. The research was conducted to determine the effects of applied nitrogen doses on plant development and turf quality. The experimental design was a split plot with turfgrass species as a whole plot, $\mathrm{N}$ doses as the sub plots. Whole plots consist of 3 warm season turfgrass species of the Bermudagrass (Tifdwarf: Cynodon dactylon x Cynodon transvaalensis; Gobi, Sydney: Cynodon dactylon L. Pers.). Nitrogen was applied at rates of $0,2,4$ and $6 \mathrm{~g} / \mathrm{m}-2$ during the 7 months. Turf color and quality of each plot were rated visually and clipping weight was determined when turf reached $8-10 \mathrm{~cm}$. In addition, on set of dormancy and color retention in fall and spring green-up were evaluated. Considering two years results that adaptation of 3 warm season turfgrass species found to be successful. In addition, $N$ applications at $4 \mathrm{~g} / \mathrm{m}-2$ gave above the acceptable color and quality of the turf. $\mathrm{N}$ rate significantly affected turfgrass color, quality and clipping yield. Tifdwarf and Gobi were identified as the first species to exit from dormancy.

Keywords: Nitrogen, Warm Season Turfgrass, Bermudagrass, Tifdwarf, Gobi, Sydney
\end{abstract}

\section{GİRiș}

Bermuda çimi (Cynodon dactylon L. Pers.), dünyanın tropik ve subtropik iklim bölgelerinde ki yeşil alanlarda yaygın şekilde kullanılan bir sıcak iklim buğdaygilidir (Emmons 1995). Bu tür kuraklığa dayanıklı, hızlı büyüme kabiliyetinde, açık yeşilden koyu yeşile kadar değişen tonlarda çim rengine sahiptir. Cynodon dactylon L. güçlü stolonları ve rizomları ile hızla yayılarak bulunduğu alanı kaplaması nedeniyle basılma veya çiğnenmeye karşı dayanıklıdır (Emmons 2000, Christians 2004). Buna karşın, düşük sıcaklıklara duyarlı ve gölgeye dayanıklılığı en az olan çim türlerinden biridir (Mcbee ve Holt 1966, Beard 1998, Emmons 2000). Golf alanları gibi oldukça yüksek kalite ve fazla bakım isteyen alanların yanı sıra, az bir bakım isteyen yol kenarlarına kadar geniş bir kullanım yelpazesine sahiptir (Emmons 1995, 2000). Bu özellikleri bakımından Bermuda çimi, ülkemizde sadece Akdeniz ve Ege bölgelerinde değil, geçiş iklim bölgelerinde tesis edilecek yeşil alanlarda da kullanım açısından önemli bir potansiyele sahiptir.
Azot; karbon, hidrojen ve oksijenden sonra çim bitkileri dokularında en çok bulunan element olması sebebiyle, çim bitkilerinin gübrelenmesinde en çok kullanılan besin elementidir (Orçun 1979). Canlı ve sağlıklı, koyu yeşil renkte bir çim tesisi ancak iyi bir azotlu gübreleme ile mümkündür (Wehner ve ark., 1988; Moore ve ark., 1996). Ancak yüksek miktarlarda ve bilinçsiz azot kullanımı, yer altı sularının ve akarsuların nitrit iyonlarınca kirlenmesine yol açmaktadır. Nitrit kirliliği insan hayatında çok önemli tehditler oluşturmakla birlikte, aşırı azot kullanımına bağlı olarak giderek artmaktadır (Ekici 2011). Bunun yanı sıra aşırı azotlu gübreleme; stratosferde yer alan ozonun parçalanmasına neden olan $\mathrm{N}_{2} \mathrm{O}$ ve $\mathrm{NO}$ gazlarının çıkışlarına sebep olmaktadır (Çöpür ve Uysal 2004). Bu nedenle azot miktarının çim bitkisinin ihtiyacı düzeyinde uygulanması büyük önem taşımaktadır. Ayrıca son yıllarda sulama suyunun teminindeki zorluklar nedeniyle, suyu daha ekonomik kullanan ve kabul edilebilir çim renk ve kalitesi veren bitkilerin araştırılması zorunluluk haline gelmiştir. 
$\mathrm{Bu}$ araştırma, farklı azot dozlarının bazı Bermuda çim çeşitlerinin, bitki gelişimi ve çim kalitesi üzerine etkilerini belirlemek amacıyla yürütülmüştür.

\section{MATERYAL ve YÖNTEM}

Araştırma, Uludağ Üniversitesi Ziraat Fakültesi Uygulama ve Araştırma Merkezi'ndeki Çim Deneme Alanı'nda 2015-2016 yıllarında, tesadüf blokları deneme deseninde bölünmüş parsellere göre 3 tekrarlamalı olarak yürütülmüştür. Ana parsellere; Bermuda çim çeşitleri, alt parsellere ise azot dozları yerleştirilmiştir. Azot kaynağı olarak \%26'lık amonyum nitrat kullanılmıştır. Azot dozları her ayın ortasinda; $0,2,4,6 \mathrm{~g} / \mathrm{m}^{2} \mathrm{~N}$ olarak 7 ay boyunca (NisanEkim) uygulanmıştır. Bitki materyalleri olarak; melez Bermuda çimi (Cynodon dactylon $\mathrm{x}$ Cynodon transvaalensis)'nin Tifdwarf, yaygın Bermuda çimi
(Cynodon dactylon L. Pers.)'nin Gobi ve Sydney çeşitleri kullanılmıştır. Ana parsel boyutları 6 x $4=24$ $\mathrm{m}^{2}$, alt parsel boyutları ise $2 \times 1=2 \mathrm{~m}^{2}$ 'dir, toplam alan ise $72 \mathrm{~m}^{2}$ 'dir.

Araştırmanın yürütüldüğü yıllara ve uzun yıllar ortalamasına ait iklim verileri Çizelge 1'de verilmiştir. Sicaklıkla ilgili veriler incelendiğinde, her iki yılda da sıcaklık ortalamasının uzun yıllar ortalamasından yüksek olduğu görülmektedir. Ortalama sıcaklıklar araştırmanın birinci yılında $15.4^{\circ} \mathrm{C}$, ikinci yılında $14.8^{\circ} \mathrm{C}$ ve uzun yıllar ortalamasında ise $14.5^{\circ} \mathrm{C}$ olarak kaydedilmiştir. Yağışla ilgili veriler incelendiğinde, yıllık yağış toplamı 2015 yılında $660.1 \mathrm{~mm}, 2016$ yılında $620.8 \mathrm{~mm}$ ve uzun y1llar ortalaması ise 695.1 mm olarak kaydedilmiştir. Denemenin her iki yılında düşen yağış miktarları uzun yıllar ortalamasının altında kalmıştır.

Çizelge 1. Denemenin yürütüldüğü Bursa İli'nde 2015, 2016 ve uzun y1llar ortalaması (UYO)'na ait sıcaklık ( $\left.{ }^{\circ} \mathrm{C}\right)$, yă̆ış $(\mathrm{mm})$ ve nem $(\%)$ değerleri.

\begin{tabular}{|c|c|c|c|c|c|c|c|c|c|}
\hline \multirow{2}{*}{ Aylar } & \multicolumn{2}{|c|}{ Ortalama Sicaklık $\left.\mathbf{(}^{\mathbf{C}}\right)$} & \multicolumn{3}{c|}{ Toplam Yağıș (mm) } & \multicolumn{3}{c|}{ Ortalama Nem (\%) } \\
\cline { 2 - 11 } & $\mathbf{2 0 1 5}$ & $\mathbf{2 0 1 6}$ & $\mathbf{U Y O}^{*}$ & $\mathbf{2 0 1 5}$ & $\mathbf{2 0 1 6}$ & $\mathbf{U Y O}$ & $\mathbf{2 0 1 5}$ & $\mathbf{2 0 1 6}$ & UYO \\
\hline Ocak & 5.4 & 5.2 & 5.4 & 112.0 & 122.2 & 87.6 & 79.0 & 80.7 & 70.0 \\
\hline Şubat & 7.3 & 11.1 & 6.3 & 74.2 & 80.7 & 74.6 & 76.5 & 76 & 68.7 \\
\hline Mart & 9.1 & 11.2 & 8.4 & 78.2 & 75.6 & 69.7 & 79.1 & 71 & 67.7 \\
\hline Nisan & 11.5 & 16.4 & 12.8 & 95.6 & 22.8 & 63.4 & 70.1 & 65.3 & 66.1 \\
\hline Mayıs & 19.3 & 18.3 & 17.6 & 36 & 67.3 & 44.3 & 64.2 & 71.2 & 62.0 \\
\hline Haziran & 21.7 & 24.5 & 22.1 & 37.8 & 36.4 & 34.3 & 72.0 & 62.3 & 57.8 \\
\hline Temmuz & 25.5 & 25.9 & 24.6 & 0.0 & 0 & 15.3 & 60.7 & 60.4 & 56.2 \\
\hline Ağustos & 26.4 & 26.2 & 24.3 & 5.6 & 7.6 & 15.7 & 61.5 & 66 & 57.3 \\
\hline Eylül & 23.6 & 21.4 & 20.1 & 98.1 & 30.8 & 39.5 & 73.2 & 67.3 & 63.8 \\
\hline Ekim & 16.4 & 15.8 & 15.2 & 93.2 & 15.8 & 68.8 & 83.7 & 74.6 & 68.7 \\
\hline Kasım & 12.7 & 10.9 & 10.7 & 26.4 & 51 & 78.5 & 78.1 & 71.6 & 69.3 \\
\hline Aralık & 5.6 & 7.4 & 7.4 & 3.0 & 110.6 & 103.4 & 76.6 & 82.4 & 68.7 \\
\hline Toplam & - & - & - & 660.1 & 620.8 & 695.1 & - & - & - \\
\hline Ortalama & 15.4 & 14.8 & 14.5 & - & - & - & 72.8 & 70.7 & 64.6 \\
\hline
\end{tabular}

*: UYO: Uzun yıllar ortalaması (1950-2015)

Araştırma alanından alınan toprak örnekleri Uludağ Üniversitesi, Ziraat Fakültesi, Toprak Bilimi ve Bitki Besleme Bölümü laboratuvarlarında analiz edilmiștir. Analiz sonucuna göre; toprak bünyesi tınlı yapıda olup, hafif alkali ( $\mathrm{pH}$ 8.48) reaksiyonludur. Fosfor ve potasyum içeriği yönünden zengin, organik maddece orta düzeyde, tuzluluk sorunu bulunmayan, azot içeriği bakımından fakir, orta kireçli sınıfın biraz altında bulunan kireçli sınıfta yer almaktadır

Çizelge 2. Deneme alanına ait toprak analizi sonuçları

\begin{tabular}{|l|l|}
\hline$\%$ Kum & 46.25 \\
\hline$\%$ Silt & 30.99 \\
\hline \% Kil & 22.76 \\
\hline Tekstür & T1n \\
\hline $\mathrm{pH}$ & 8.48 \\
\hline EC, $\mu \mathrm{S} \mathrm{cm}-1$ & 468 \\
\hline KDK, meq $100 \mathrm{~g}-1$ & 15.21 \\
\hline Kireç, \% & 4.28 \\
\hline Organik madde \% & 2.091 \\
\hline$\% \mathrm{~N}$ & 0.106 \\
\hline Alınabilir P, mg kg-1 & 30.95 \\
\hline Toplam K mg kg-1 & 5180 \\
\hline
\end{tabular}


Araştırmada her bir y1l için 4 biçim yapılmış olup toplam 8 biçim gerçekleştirilmiştir. Alt parsellerde kenar tesirleri alındıktan sonra kalan $0.5 \times 1$ m'lik alandan yeşil otlar alınmış, $70^{\circ} \mathrm{C}$ de 48 saat kurutularak tartılmıştır (Bilgili ve Açıkgöz 2005; Bilgili ve Açıkgöz 2011; Bilgili ve ark. 2011). Denemede sulama için açık su yüzeyi buharlaşma yönteminden yararlanılmıştır (Emekli ve ark. 2007). Bu yöntemde buharlaşma kabında meydana gelen buharlaşmaya etkili olan iklim faktörlerinin tamamı, aynı zamanda bitki su tüketimine de benzer biçimde etkili olduğundan oldukça sağlıklı sonuçların elde edilmesi sağlanmaktadır (Cemek ve ark. 2004). Mayıs-Ekim ayları arasında, günlük olarak A sınıfı buharlaşma kabındaki buharlaşmanın \%100'ü olacak şekilde sulamada kullanılmıştır (Açıkgöz ve ark 2010). Çim renk ve kalitesi 1-9 skalasına göre her biçimde ve biçim yapılmayan dönemlerde aylık olarak alınmıştır. Renk 1: sarı, 6: kabul edilebilir ve 9: koyu yeşil; kalite: 1-9 değerleri, üniformite, sıklık, renk ve yabanc1 ot yoğunluğuna göre 1: çok kötü, 6: kabul edilebilir ve 9: mükemmel olacak şekilde alınmışlardır
(Sills ve Carrow 1983, Mehall ve ark. 1983, Goatley ve ark. 1994, Bilgili ve Açıkgöz 2005). Bitkilerin 'Dormanside Kalma Süreleri'ni belirlemek amaciyla parsellerde; sonbaharda tam sararma, ilkbaharda ise ilk yeşil sürgün, $\% 50$ yeşil sürgün ve $\% 100$ yeşil sürgün oluşum tarihleri kaydedilmiş ve elde edilen zaman aralıkları gün olarak belirlenmiştir (Salman 2008).

Tüm hesaplamalar bilgisayar aracılı̆̆ ile JMP7 programından yararlanılarak gerçekleştirilmiştir. Önemlilik testlerinde 0.01 ve 0.05 , farklı gurupların belirlenmesinde ise 0.05 olasılık düzeyi kullanılmıştır. Araştırma sonuçlarının sunulduğu çizelgelerde (*) ve (**) işaretleri sırası ile 0.01 ve 0.05 olasılık düzeyinde istatistiki olarak önemliliği, (öd) ise istatistiki olarak önemli olmamayı ifade etmektedir. Ortalamalar arası farklılık LSD testi ile 0.05 düzeyinde belirlenmiştir.

\section{ARAŞTIRMA SONUÇLARI ve TARTIŞMA}

Çizelge 3 ve 4'de çim çeşitleri, azot dozları ve çim çeşitleri x azot dozları interaksiyonuna ait renk, kalite ve kuru ot varyans analiz sonuçları yer almaktadır.

Çizelge 3. 2015 yılı çim renk, kalite ve kuru ot değerlerine ait varyans analiz sonuçları

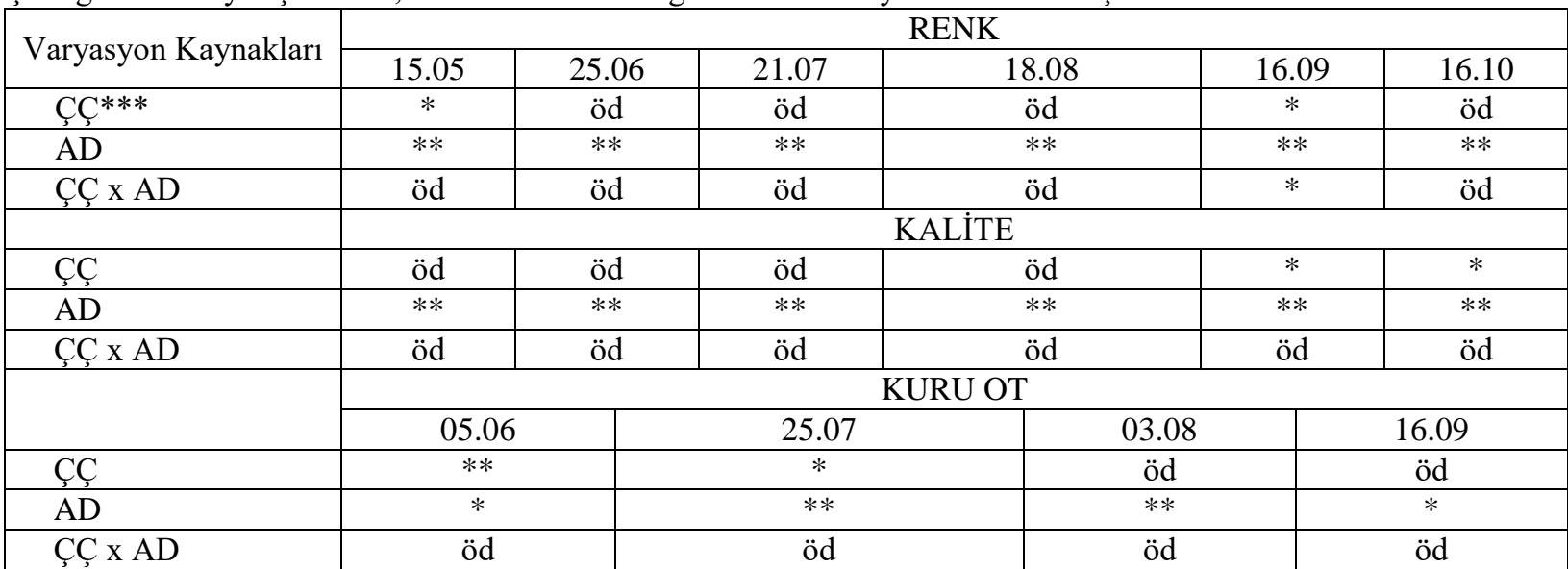

*: 0,05 olasılık düzeyinde istatistiki olarak önemlidir,

**:0,01 olasıl1k düzeyinde istatistiki olarak önemlidir,

***: ÇÇ: Çim çeşitleri, AD: Azot dozları

Çizelge 4. 2016 yılı çim renk, kalite ve kuru ot değerlerine ait varyans analiz sonuçları

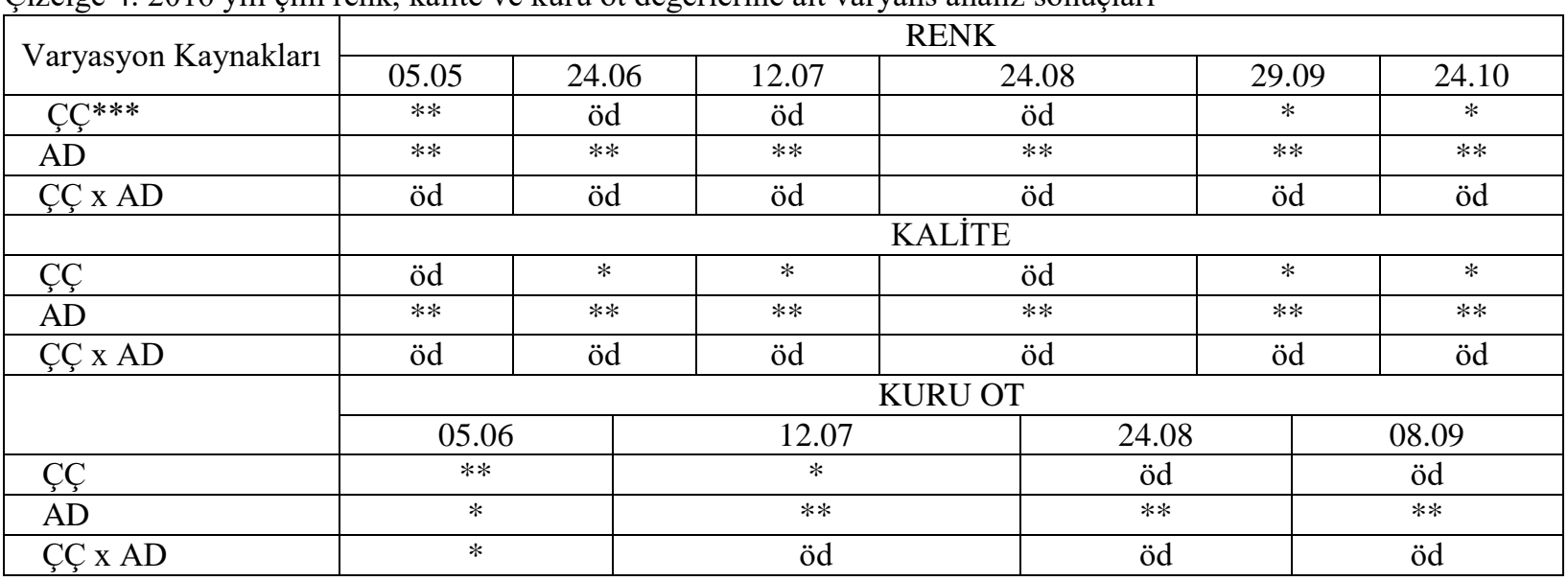

Azot dozları her iki yılda da tüm renk, kalite ve kuru ot parametreleri bakımından istatistiksel anlamda önemli bulunmuştur. Farklı Bermuda çim çeşitleri arasında, sıcak iklim çim bitkileri için optimum sıcaklık 
koşullarının yakalandığı Haziran, Temmuz ve Ağustos aylarında renk ve kalite değerleri bakımından istatistiksel bir farklılık görülmemiştir. Ancak optimum sıcaklık isteklerinin dışına çıkıldığg ilkbahar ve sonbahar aylarında renk ve kalite bakımından çeşitler arasında farklılıklar oluşmuştur.

Çim çeşitleri ve azot dozlarına ait renk değerleri Çizelge 5 ve Çizelge 6'da, kalite değerleri Çizelge 7 ve Çizelge 8'de ve kuru ot değerleri Çizelge 9 ve Çizelge 10 'da yer almaktadır. Dormansi Gün Sayılarına ait veriler ise Çizelge 11 'de verilmiştir.

\section{Renk}

Çizelge 5'te yer alan 2015 yılı çim çeşitleri ve azot dozlarına ait renk değerleri incelendiğinde; Mayıs ayında Tifdwarf ve Gobi çeşidi aynı istatistiki grupta yer alarak en yüksek çim renk değerini, Sydney çeşidi ise 5.8 renk değeri ile kabul edilebilir renk değerinin altında bir renk değeri vermiştir. Eylül ayında ise en yüksek renk değeri Sydney çeşidinden alınmıştır. Haziran, Temmuz ve Ağustos aylarında alınan renk gözlemlerinde çeşitler arasında istatistiksel farklılıklar bulunmamıştır.

Çizelge 5. 2015 çim çeşitleri ve azot dozlarına ait çim renk değerleri

\begin{tabular}{|c|c|c|c|c|c|c|}
\hline \multirow{2}{*}{ ÇÇ } & \multicolumn{7}{|c|}{ RENK } \\
\cline { 2 - 7 } & 15.05 & 25.06 & 21.07 & 18.08 & 16.09 & 16.10 \\
\hline $1^{*}$ & $6.2 \mathrm{a}$ & 6.7 & 7.1 & 7.3 & $6.7 \mathrm{~b}$ & 6.0 \\
\hline 2 & $6.3 \mathrm{a}$ & 6.7 & 7.1 & 7.3 & $6.5 \mathrm{~b}$ & 6.1 \\
\hline 3 & $5.8 \mathrm{~b}$ & 6.9 & 7.0 & 7.3 & $7.1 \mathrm{a}$ & 5.8 \\
\hline LSD (0.05) & 0.305 & öd & öd & öd & 0.269 & öd \\
\hline $\mathrm{AD}$ & $3.5 \mathrm{~d}$ & $4.0 \mathrm{~d}$ & $4.8 \mathrm{~d}$ & $5.0 \mathrm{~d}$ & $5.0 \mathrm{~d}$ & $3.4 \mathrm{~d}$ \\
\hline 0 & $6.0 \mathrm{c}$ & $6.7 \mathrm{c}$ & $6.7 \mathrm{c}$ & $7.0 \mathrm{c}$ & $6.3 \mathrm{c}$ & $5.8 \mathrm{c}$ \\
\hline 2 & $6.8 \mathrm{~b}$ & $7.7 \mathrm{~b}$ & $7.8 \mathrm{~b}$ & $8.0 \mathrm{~b}$ & $7.2 \mathrm{~b}$ & $6.8 \mathrm{~b}$ \\
\hline 4 & $8.1 \mathrm{a}$ & $8.6 \mathrm{a}$ & $8.8 \mathrm{a}$ & $9.0 \mathrm{a}$ & $8.5 \mathrm{a}$ & $7.6 \mathrm{a}$ \\
\hline 6 & 0.248 & 0.587 & 0.508 & 0.332 & 0.293 & 0.248 \\
\hline LSD $(0.05)$ & \multicolumn{7}{|l|}{}
\end{tabular}

1*.Tifdwarf, 2.Gobi 3.Sydney

Azot dozlarının renk değerleri üzerine etkisine bakıldığında, $6 \mathrm{~g} / \mathrm{m}^{2} \mathrm{~N}$ dozunun tüm gözlemlerde en yüksek renk değeri verdiği, buna karşılık kontrol parsellerinde ise en düşük renk değerlerinin elde edildiği görülmektedir. $2 \mathrm{~g} / \mathrm{m}^{2} \mathrm{~N}$ dozu ise Ekim ayı haricinde kabul edilebilir seviyenin üzerinde renk değerleri vermiştir (Çizelge 5). Azot, kloroplastlarda bulunan klorofil molekülünün yapısal bir üyesidir ve ortamda bol bulunduğunda klorofil molekül sayısını arttırmaktadır. Renk özelliği klorofil miktarına bağlıdır (Türkan 2008). Bilgili ve Açıkgöz (2011) artan azot dozlarının çim bitkilerinde renk, kalite, kaplama oranı ve kuru ot gibi özellikleri artırdığını bildirmişlerdir. Araştırmamızda da benzer şekilde artan azot dozuyla birlikte renk değerlerinin arttığ tespit edilmiştir.

Çizelge 6'da yer alan 2016 y1li çim çeşitleri ve azot dozlarına ait renk değerleri incelendiğinde 2016 yılında Mayıs ve Ekim aylarında yapılan gözlemlerde Tifdwarf ve Gobi çeşitleri en yüksek renk değerlerini, Sydney çeşidi ise en düşük renk değerlerini vermiştir. Eylül ayındaki gözlemde ise Gobi çeşidi en yüksek renk değerini vermiştir. Haziran, Temmuz ve Ağustos aylarında yapılan gözlemlerde çim çeşitleri arasındaki farklılıklar önemsiz bulunmuştur.

Çizelge 6. 2016 yılı çim çeşitleri ve azot dozlarına ait çim renk değerleri

\begin{tabular}{|c|c|c|c|c|c|c|}
\hline \multirow{2}{*}{ ÇÇ } & \multicolumn{7}{|c|}{ RENK } \\
\cline { 2 - 7 } & 05.05 & 24.06 & 12.07 & 24.08 & 29.09 & 24.10 \\
\hline $1^{*}$ & $6.6 \mathrm{a}$ & 6.9 & 7.2 & 7.3 & $6.7 \mathrm{~b}$ & $5.1 \mathrm{a}$ \\
\hline 2 & $6.6 \mathrm{a}$ & 7.0 & 7.1 & 7.2 & $8.3 \mathrm{a}$ & $4.8 \mathrm{a}$ \\
\hline 3 & $6.0 \mathrm{~b}$ & 6.9 & 7.0 & 7.6 & $7.3 \mathrm{~b}$ & $4.4 \mathrm{~b}$ \\
\hline LSD (0.05) & 0.249 & öd & öd & öd & 0.305 & 0.288 \\
\hline AD & $4.4 \mathrm{c}$ & $5.0 \mathrm{~d}$ & $5.0 \mathrm{~d}$ & $5.0 \mathrm{~d}$ & $4.7 \mathrm{~d}$ & $2.8 \mathrm{~d}$ \\
\hline 0 & $6.2 \mathrm{~b}$ & $6.4 \mathrm{c}$ & $6.6 \mathrm{c}$ & $7.0 \mathrm{c}$ & $6.7 \mathrm{c}$ & $3.8 \mathrm{c}$ \\
\hline 2 & $6.7 \mathrm{~b}$ & $7.4 \mathrm{~b}$ & $7.6 \mathrm{~b}$ & $8.4 \mathrm{~b}$ & $7.6 \mathrm{~b}$ & $5.4 \mathrm{~b}$ \\
\hline 4 & $8.0 \mathrm{a}$ & $8.8 \mathrm{a}$ & $9.0 \mathrm{a}$ & $9.0 \mathrm{a}$ & $8.5 \mathrm{a}$ & $6.8 \mathrm{a}$ \\
\hline 6 & 0.894 & 0.597 & 0.576 & 0.384 & 0.656 & 0.665 \\
\hline LSD $(0.05)$ & \multicolumn{7}{|l|}{}
\end{tabular}

1*.Tifdwarf, 2.Gobi 3.Sydney

Azot dozlarının renk değerleri üzerine etkisine bakıldığında, $6 \mathrm{~g} / \mathrm{m}^{2} \mathrm{~N}$ dozunun tüm gözlemlerde en yüksek renk değeri verdiği, buna karş1lık kontrol parsellerinde ise en düşük renk değerlerinin elde edildiği görülmektedir. Mayıs ayında 2 ve $4 \mathrm{~g} / \mathrm{m}^{2} \mathrm{~N}$ dozları aynı istatistiki grupta yer alarak benzer sonuçlar vermiştir. $2 \mathrm{~g} / \mathrm{m}^{2} \mathrm{~N}$ dozu Ekim ayı haricinde kabul edilebilir seviyenin üzerinde renk değerleri verdiği 
gözlenmiştir. Bilgili ve Açıkgöz (2005), Bursa'da yürüttükleri bir çalışmada aylık $5.0 \mathrm{~g} \mathrm{~m}^{2} \mathrm{~N}$ dozu ile kaliteli bir bakım yapılabileceğini belirtmişlerdir.

Sıcak iklim çim bitkileri en iyi gelişmelerini optimum sıcaklıkların yaşandığı $\left(25-35^{\circ} \mathrm{C}\right)$ yaz aylarında sergilemektedir. $\mathrm{Bu}$ değerlerin altında sıcaklıkların yaşandığı ilkbahar ve sonbahar aylarında ise daha düşük çim renk değerleri alınmaktadır. Buradan, araştırmada 2016 yılı Mayıs $\left(18.3^{\circ} \mathrm{C}\right)$ ve Ekim $\left(15.8^{\circ} \mathrm{C}\right)$ aylarında daha düşük renk değerleri elde edilmesinin sıcaklıkların sıcak iklim çim bitkileri için optimum seviyenin altında olmasından kaynaklandığ söylenebilir (Patton ve Boyd 2007, Trenholm ve Unruh 2007, Trenholm ve ark. 2007).

\section{Kalite}

Çizelge 7'de yer alan 2015 y1lı Bermuda çim çeşitleri ve azot dozlarına ait kalite değerleri incelendiğinde; Eylül ve Ekim aylarında çim çeşitleri arasında istatistiksel farklılıklar tespit edilmiş, Mayıs, Haziran, Temmuz ve Ağustos ayları ise önemsiz bulunmuştur.

Çizelge 7. 2015 yılı çim çeşitleri ve azot dozlarına ait çim kalite değerleri

\begin{tabular}{|c|c|c|c|c|c|c|}
\hline \multirow{2}{*}{ ÇÇ } & \multicolumn{6}{|c|}{ KALİTE } \\
\hline & 15.05 & 25.06 & 21.07 & 18.08 & 16.09 & 16.10 \\
\hline $1 *$ & 5.8 & 6.5 & 6.7 & 7.2 & $6.5 \mathrm{~b}$ & $5.4 \mathrm{~b}$ \\
\hline 2 & 5.8 & 6.5 & 6.9 & 7.0 & $6.4 \mathrm{~b}$ & $6.1 \mathrm{a}$ \\
\hline 3 & 6.1 & 6.6 & 7.0 & 7.1 & $6.8 \mathrm{a}$ & $5.3 \mathrm{~b}$ \\
\hline $\operatorname{LSD}(0.05)$ & öd & öd & öd & öd & 0.305 & 0.432 \\
\hline \multicolumn{7}{|l|}{$\mathrm{AD}$} \\
\hline 0 & $3.7 \mathrm{~d}$ & $4.0 \mathrm{~d}$ & $4.8 \mathrm{c}$ & $5.0 \mathrm{~d}$ & $5.0 \mathrm{~d}$ & $3.4 \mathrm{~d}$ \\
\hline 2 & $5.8 \mathrm{c}$ & $6.5 \mathrm{c}$ & $6.8 \mathrm{~b}$ & $6.8 \mathrm{c}$ & $5.7 \mathrm{c}$ & $5.5 \mathrm{c}$ \\
\hline 4 & $6.5 \mathrm{~b}$ & $7.3 \mathrm{~b}$ & $7.3 \mathrm{~b}$ & $7.7 \mathrm{~b}$ & $7.1 \mathrm{~b}$ & $6.4 \mathrm{~b}$ \\
\hline 6 & $7.3 \mathrm{a}$ & $8.3 \mathrm{a}$ & $8.4 \mathrm{a}$ & $8.6 \mathrm{a}$ & $8.4 \mathrm{a}$ & $7.0 \mathrm{a}$ \\
\hline LSD (0.05) & 0.457 & 0.576 & 0.627 & 0.313 & 0.576 & 0.457 \\
\hline
\end{tabular}

*: 1.Tifdwarf, 2. Gobi 3. Sydney

En yüksek çim kalite değerleri Eylül ayında Sydney çeşidinden, Ekim ayında ise Gobi çeşidinden alınmıştır. Sydney çeşidi ise Ekim ayında 5.3 kalite değeri ile kabul edilebilir değerin altında kalmıştır.

Azot dozlarının kalite değerleri üzerine etkisine bakıldığında, $6 \mathrm{~g} / \mathrm{m}^{2} \mathrm{~N}$ dozunun tüm gözlemlerde en yüksek renk değeri verdiği, buna karşılık kontrol parsellerinde ise en düşük renk değerlerinin elde edildiği görülmektedir. Mayıs, Eylül ve Ekim aylarında yapılan gözlemlerde ise $2 \mathrm{~g} / \mathrm{m}^{2} \mathrm{~N}$ dozu kabul edilebilir kalite değerinin altında sonuçlar vermiştir (Çizelge 7).

Çizelge 8. 2016 yılı çim çeşitleri ve azot dozlarına ait çim kalite değerleri

\begin{tabular}{|c|c|c|c|c|c|c|}
\hline \multirow{2}{*}{ ÇÇ } & \multicolumn{7}{|c|}{ KALİTE } \\
\cline { 2 - 7 } & 05.05 & 24.06 & 12.07 & 24.08 & 29.09 & 24.10 \\
\hline $1^{*}$ & 6.2 & $6.5 \mathrm{ab}$ & $6.8 \mathrm{ab}$ & 7.3 & $6.1 \mathrm{~b}$ & $4.8 \mathrm{a}$ \\
\hline 2 & 5.9 & $6.2 \mathrm{~b}$ & $6.4 \mathrm{~b}$ & 7.2 & $6.3 \mathrm{~b}$ & $4.3 \mathrm{ab}$ \\
\hline 3 & 5.9 & $6.8 \mathrm{a}$ & $7.0 \mathrm{a}$ & 7.4 & $6.9 \mathrm{a}$ & $4.1 \mathrm{~b}$ \\
\hline LSD $(0.05)$ & od & 0.381 & 0.367 & od & 0.432 & 0.444 \\
\hline AD & $4.0 \mathrm{~d}$ & $4.3 \mathrm{~d}$ & $4.4 \mathrm{~d}$ & $4.7 \mathrm{~d}$ & $4.2 \mathrm{~d}$ & $2.6 \mathrm{~d}$ \\
\hline 0 & $5.8 \mathrm{c}$ & $6.2 \mathrm{c}$ & $6.4 \mathrm{c}$ & $7.0 \mathrm{c}$ & $6.0 \mathrm{c}$ & $3.8 \mathrm{c}$ \\
\hline 2 & $6.5 \mathrm{~b}$ & $7.0 \mathrm{~b}$ & $7.3 \mathrm{~b}$ & $8.3 \mathrm{~b}$ & $7.2 \mathrm{~b}$ & $4.7 \mathrm{~b}$ \\
\hline 4 & $7.5 \mathrm{a}$ & $8.3 \mathrm{a}$ & $8.6 \mathrm{a}$ & $9.0 \mathrm{a}$ & $8.2 \mathrm{a}$ & $6.3 \mathrm{a}$ \\
\hline 6 & 0.508 & 0.665 & 0.443 & 0.384 & 0.332 & 0.496 \\
\hline
\end{tabular}

*: 1.Tifdwarf, 2. Gobi 3. Sydney

Çizelge 8'de yer alan 2016 yılı çim çeşitleri ve azot dozlarına ait kalite değerleri incelendiğinde; en yüksek çim kalite değerlerini Haziran ve Temmuz aylarında Tifdwarf ve Sydney, Eylül ayında Sydney, Ekim ayında ise Tifdwarf ve Gobi çeşitleri vermiştir. En düşük değerler Haziran ve Temmuz aylarında Gobi, Eylül ayında Tifdwarf ve Gobi Ekim ayında ise Gobi ve Sydney çeşitleri vermiştir. Mayıs ve Ağustos ayları ise önemsiz bulunmuştur.
$6 \mathrm{~g} / \mathrm{m}^{2} \mathrm{~N}$ dozunun tüm gözlemlerde en yüksek kalite değeri verdiği, buna karşılık kontrol parsellerinde ise en düşük kalite değerlerinin elde edildiği görülmektedir. 2 $\mathrm{g} / \mathrm{m}^{2} \mathrm{~N}$ dozu ise Mayıs ve Ekim gözlemleri haricinde kabul edilebilir seviyenin üzerinde kalite değerleri verdiği gözlenmiştir (Çizelge 8). Artan oranlarda azot dozu uygulamaları çim kalitesine olumlu etki yapmaktadir (Trenholm ve Unruh 2007, Bilgili ve Açıkgöz 2011). Araştırmamızda bu sonuçlara benzer 
şekilde olup yüksek azot oranının çim kalitesini arttırdığ 1 tespit edilmiştir.

\section{Kuru ot}

Araştırmada 2015-2016 yılları çim çeşitleri ve azot dozlarına ait kuru ot miktarları Çizelge 8 ve Çizelge 9'da sunulmuştur. 2015 y1lına ait kuru ot verilerinin yer aldığı Çizelge 9 incelendiğinde, toplam 4 biçimin yapıldığ1 ve bu biçimlerden sadece Haziran ve Temmuz aylarındaki biçimlerde çim çeşitleri arasında kuru ot değerleri bakımından istatistiksel farklılıklar olduğu görülmektedir. Ağustos ve Eylül ayları ise önemsiz bulunmuştur. Önemli etkilerde bulunduğu Haziran ve Temmuz aylarında en yüksek kuru ot değeri Gobi çeşidinden alınmıştır.

Azot dozlarının kuru ot değerleri üzerine etkisine bakıldığında, Haziran ayında 4 ve $6 \mathrm{~g} / \mathrm{m}^{2} \mathrm{~N}$ dozları aynı istatistiki grupta yer alarak birlikte, diğer aylarda ise 6 $\mathrm{g} / \mathrm{m}^{2} \mathrm{~N}$ dozu tek başına en yüksek kuru ot değerlerini vermiştir. $0 \mathrm{~g} / \mathrm{m}^{2} \mathrm{~N}$ dozunun tüm biçimlerde en düşük kuru ot değerleri verdiği görülmektedir (Çizelge 9). Nizam (2009), azot uygulamasının biyolojik verimde önemli derecede artışa neden olduğunu bildirmiştir.

Çizelge 9. 2015 yılı çim çeşitleri ve azot dozlarına ait çim kuru ot verimleri $\left(\mathrm{g} / \mathrm{m}^{2}\right)$

\begin{tabular}{|c|c|c|c|c|}
\hline \multirow{2}{*}{ ÇÇ } & \multicolumn{4}{|c|}{ KURU OT } \\
\cline { 2 - 5 } & 05.06 & 25.07 & 03.08 & 16.09 \\
\hline $1^{*}$ & $89.3 \mathrm{~b}$ & $73.9 \mathrm{~b}$ & 90.3 & 142.7 \\
\hline 2 & $132.5 \mathrm{a}$ & $91.5 \mathrm{a}$ & 84.1 & 138.0 \\
\hline 3 & $75.5 \mathrm{~b}$ & $78.6 \mathrm{ab}$ & öd & öd \\
\hline LSD $(0.05)$ & 15.1 & 13.4 & $33.2 \mathrm{~d}$ & $54.8 \mathrm{c}$ \\
\hline $\mathrm{AD}$ & \multicolumn{5}{|c|}{} \\
\hline 0 & $60.7 \mathrm{c}$ & $34.8 \mathrm{~d}$ & $66.3 \mathrm{c}$ & $115.6 \mathrm{~b}$ \\
\hline 2 & $86.8 \mathrm{bc}$ & $62.2 \mathrm{c}$ & $104.6 \mathrm{~b}$ & $152.6 \mathrm{~b}$ \\
\hline 4 & $113.8 \mathrm{ab}$ & $90.6 \mathrm{~b}$ & $140.3 \mathrm{a}$ & $252.3 \mathrm{a}$ \\
\hline 6 & $135.1 \mathrm{a}$ & $137.6 \mathrm{a}$ & 17.2 & 43.7 \\
\hline LSD $(0.05)$ & 28.2 & 10.5 &
\end{tabular}

\section{*: 1.Tifdwarf, 2. Gobi 3. Sydney}

2016 yılına ait kuru ot verilerinin yer aldığ 1 Çizelge 10 incelendiğinde, 2015 yılında olduğu gibi sadece 4 biçimin yapıldığı ve yine Haziran ve Temmuz aylarındaki kuru ot verileri bakımından çim çeşitleri arasında istatistiksel farklılıkların olduğu görülmektedir. Ağustos ve Eylül aylarındaki biçimlerde ise çim çeşitleri arasındaki farklılıklar önemsiz bulunmuştur. Haziran ayında en yüksek kuru ot değerlerini Tifdwarf ve Gobi çeşidi birlikte, Temmuz ayında ise Gobi çeşidi tek başına vermiştir. En düşük kuru ot değerini Haziran ayında Sydney çeşidi, Temmuz ayında ise Tifdwarf ve Sydney çeşitleri birlikte vermişlerdir.

Çizelge 10. 2016 yılı çim çeşitleri ve azot dozlarına ait çim kuru ot verimleri $\left(\mathrm{g} / \mathrm{m}^{2}\right)$

\begin{tabular}{|c|c|c|c|c|}
\hline \multirow{2}{*}{ ÇÇ } & \multicolumn{5}{|c|}{ KURU OT } \\
\cline { 2 - 5 } & 05.06 & 12.07 & 24.08 & 08.09 \\
\hline $1^{*}$ & $137.9 \mathrm{a}$ & $102.3 \mathrm{~b}$ & 119.8 & 98.5 \\
\hline 2 & $149.9 \mathrm{a}$ & $129.3 \mathrm{a}$ & 121.6 & 84.3 \\
\hline 3 & $85.1 \mathrm{~b}$ & $87.6 \mathrm{~b}$ & 136.8 & öd \\
\hline LSD(0.05) & 14.1 & 19.5 & $36.5 \mathrm{~d}$ & $36.0 \mathrm{~d}$ \\
\hline AD & $67.5 \mathrm{~d}$ & $27.5 \mathrm{~d}$ & $101.1 \mathrm{c}$ & $73.6 \mathrm{c}$ \\
\hline 0 & $103.8 \mathrm{c}$ & $69.1 \mathrm{c}$ & $161.6 \mathrm{~b}$ & $108.2 \mathrm{~b}$ \\
\hline 2 & $139.4 \mathrm{~b}$ & $140.0 \mathrm{~b}$ & $204.2 \mathrm{a}$ & $145.2 \mathrm{a}$ \\
\hline 4 & $186.4 \mathrm{a}$ & $189.0 \mathrm{a}$ & 26.6 & 26.1 \\
\hline 6 & 30.3 & 22.5 & \\
\hline
\end{tabular}

\section{*: 1.Tifdwarf, 2. Gobi 3. Sydney}

2016 yılında azot dozlarının kuru ot değerleri üzerine etkisine bakıldığında, artan dozlarla birlikte verimin giderek arttığ 1 ve özellikle $6 \mathrm{~g} / \mathrm{m}^{2} \mathrm{~N}$ dozunda en yüksek verime ulaşıldığı görülmektedir. $6 \mathrm{~g} / \mathrm{m}^{2} \mathrm{~N}$ dozunun tüm biçimlerde en yüksek kuru ot değerleri verdiği, buna karşılık kontrol parsellerinin ise en düşük kuru ot değerleri verdiği görülmektedir. Bermuda çiminde çevresel faktörlerin yanı sıra azot uygulaması kuru ot verimini etkileyen önemli bir unsurdur (Brink ve ark. 2002, Read ve ark. 2006).
2015 yılı Eylül ayında hem çim çeşitleri hem de azot dozları bakımından yaz aylarında elde edilen kuru ot verimlerine göre önemli bir artış görülmekte, bu artış 2016 Eylül ayı ile kıyaslandığında da fark edilmektedir. Çizelge 1'de yer alan sıcaklık verileri incelendiğinde, 2015 yılı Eylül ayında $23.6^{\circ} \mathrm{C}^{\prime}$ lik bir ortalama sicaklık yaşandığı ve bu sıcaklığın yaz ayları ortalamasına yakın bir değer olduğu, üstelik 2016 yılı $\left(21.4^{\circ} \mathrm{C}\right)$ ve uzun yıllar $\left(20.1^{\circ} \mathrm{C}\right)$ ortalama sicaklıklarından daha yüksek olduğu görülmektedir. Dolayısıyla 2015 yılı Eylül 
ayında kuru ot veriminde yaşanan artışı yüksek sıcaklığa bağlamamız mümkündür. Newman ve ark (2007), genellikle sıcaklığın ve fotoperiyotda azalmanın yeşil ot verimini azalttığını, yine Burton ve ark. (1988) da, 13 saatin altındaki gün uzunluğunun bermuda çim bitkisinde verimi düşürdüğünü bildirmişlerdir.

\section{Dormansi Gün Sayısı}

Canlıların büyüme ve gelişmeleri üzerine en önemli iklim faktörlerinden biri sıcaklıktır. Bitkilerin metabolik etkinliklerini simgeleyen biyokimyasal reaksiyonlar, esas olarak ortam sicaklığına yakından bağlı bulunduğundan, sıcaklığın düşmesi ve ortamın soğuması durumunda bu fizyolojik olaylar önce yavaşlayıp daha sonra durmaktadır (Salisbury ve Ross 1992). Sicak iklim çim bitkilerinde kış mevsiminde sararma şeklinde ortaya çıkan "dormansi”, büyümenin durması ve klorofil moleküllerinin parçalanması sonucu oluşmakta, sadece stolon ve rizomların boğumlarında kalan canlı büyüme noktaları kışı canlı geçirmektedir (Avcioğlu 1997).

Salmanın (2008) bildirdiği gibi dormansi giriş ve çıkış tarihleri $4 \mathrm{~g} / \mathrm{m}^{2}$ azot dozu üzerinden alınmıştır. Çizelge 11 incelendiğinde, Tifdwarf ve Gobi'nin dormansiden ilk çıkan çeşitler olduğu gözlenmiş, bu çeşitleri Sydney çeşidi takip etmiştir. Tifdwarf ve Gobi çeşitleri tam sararmadan sonra $\% 100$ yeşil sürgün aşamasına 130 günde, Sydney çeşidi ise 135 günde ulaşmıştır. Araştırmada incelenen Bermuda çim çeşitlerinin tam sararma ile tam yeşil rengin oluştuğu tarihler arasındaki periyodu simgeleyen uyku süreci açısından en iyi sonucu her iki yılda da Tifdwarf ve Gobi çeşitleri vermiştir.

Çizelge 11. 2015-2016 Dönemi Çim Çeşitlerinin Dormansi Gün Sayısı

\begin{tabular}{|c|c|c|c|c|c|c|c|}
\hline \multirow[b]{2}{*}{$\begin{array}{c}\text { Çim } \\
\text { Çeşitleri }\end{array}$} & \multicolumn{7}{|c|}{ Dormanside Kalma Süreleri } \\
\hline & $\begin{array}{c}\text { Tam } \\
\text { Sararma } \\
\text { Tarihi }\end{array}$ & $\begin{array}{l}\text { İlk Yeşil } \\
\text { Sürgün } \\
\text { Tarihi }\end{array}$ & $\begin{array}{c}\text { Tam } \\
\text { Sararma } \\
\text { İlk Yeşil } \\
\text { Sürgün } \\
\text { Arası Gün } \\
\text { Sayısı }\end{array}$ & $\begin{array}{l}\text { \%50 Yeşil } \\
\text { Sürgün } \\
\text { Tarihi }\end{array}$ & $\begin{array}{c}\text { Tam } \\
\text { Sararma } \\
\text { \%50 Yeşil } \\
\text { Sürgün } \\
\text { Arası Gün } \\
\text { Sayısı }\end{array}$ & $\begin{array}{c}\text { \%100 Yeşil } \\
\text { Sürgün } \\
\text { Tarihi }\end{array}$ & $\begin{array}{c}\text { Tam } \\
\text { Sararma } \\
\% 100 \\
\text { Yeşil } \\
\text { Sürgün } \\
\text { Arası } \\
\text { Gün } \\
\text { Sayısı }\end{array}$ \\
\hline $1 *$ & 12.12 .2015 & 03.04 .2016 & 113 & 10.04 .2016 & 120 & 20.04 .2016 & 130 \\
\hline 2 & 12.12 .2015 & 03.04 .2016 & 113 & 10.04 .2016 & 120 & 20.04 .2016 & 130 \\
\hline 3 & 10.12 .2015 & 05.04 .2016 & 115 & 12.04 .2016 & 122 & 25.04 .2016 & 135 \\
\hline
\end{tabular}

*: 1.Tifdwarf, 2. Gobi 3. Sydney

Yeşil alanların yıl boyunca, estetik ve doyurucu yeşilliklerini koruması, tüketicilerin en önemli istekleri arasındadır (Açıkgöz 1994, Avcıoğlu 1997, Altan 1989). Ancak, sicak iklim çimlerinin tropik koşullar dışında bunu sağlamaları mümkün olmamakta ve özellikle kış mevsiminde dormansi sürecine girerek ilkbahara kadar sararmış ve kısmen ölü dokularıyla alanı kaplamaya devam etmektedirler. $\mathrm{Bu}$ çim bitkilerinin sararma sürecinin kısalığı, yukarıda açıklanan tercihler nedeniyle, ayrı bir önem kazanmaktadır (Salman 2008).

Bermuda çimi toprak sıcaklığının $10^{\circ} \mathrm{C}$ 'nin altına düştüğü koşullarda kısa sürede dinlenmeye girerek sararmakta, sicaklık $15-20^{\circ} \mathrm{C}^{\prime}$ ye yükselinceye kadar dinlenme halinde kalmakta ve $25-35^{\circ} \mathrm{C}$ sicakliklarda optimum büyüme ve gelişme göstermektedir (Christians, 2004). Bu nedenle çeşitlerin Bursa ekolojik koşullarında dormansiye girmeleri beklenen bir durumdur. Salman (2008) İzmir koşullarında yürüttüğü doktora çalışmasında, Cynodon dactylon'a ait Standart ve SR9554 adlı çeşitlerin oluşturduğu parsellerin, sirasıyla ilk y1l 134. günde, ikinci yıl ise 115 ve 129 . günlerde tam dormansiden çıktıklarını bildirmiştir.

\section{SONUC}

İki yıl süren araştırmanın sonuçlarına göre, Bermuda çim türünün çeşitleri arasında, sıcak iklim çim bitkileri için uygun koşulların sağlandığı yaz aylarında önemli farkl11ıklar bulunmayıp üç çeşitte başarılı bulunmuştur. Azot kaynağı olarak kullanılan amonyum nitratın $6 \mathrm{~g} / \mathrm{m}^{2}$ azot dozu, tüm gözlemlerde en iyi çim renk ve kalite değerlerini vermiştir. $4 \mathrm{~g} / \mathrm{m}^{2}$ azot dozu tüm gözlemler de kabul edilebilir renk ve kalite değerleri verirken, $2 \mathrm{~g} / \mathrm{m}^{2}$ azot dozunun ilkbahar ve sonbahar aylarında kabul edilebilir seviyenin altında sonuçlar vermiştir. Dolayısıyla $4 \mathrm{~g} / \mathrm{m}^{2}$ azot dozu ile kabul edilebilir çim renk ve kalitesi elde edilebileceği, aynı zamanda maliyeti düşük ve çevre dostu bir gübreleme uygulaması olacağı söylenebilir.

Gobi çeşidinden yüksek kuru ot alınması nedeniyle biçinti artığının bertarafının bakım maliyetlerini artıracağı, Tifdwarf ve özellikle Sydney çeşidinin daha az kuru ot vermesi nedeniyle bakım maliyetinin düşük olacağı söylenebilir.

Kış dönemini dormant halde geçiren bu üç sıcak iklim çeşidin yaz aylarında üstün performans sergilediği gözlenmiştir.

\section{TEŞEKKÜR}

$\mathrm{Bu}$ bildiri $112 \mathrm{O} 745$ nolu Tübitak projesinden üretilmiştir. Tübitak'a vermiş olduğu destekten dolayı teşekkür ederiz.

\section{KAYNAKLAR}

Açıkgöz E, Bilgili U, Yazgan S, Kumral A, Candoğan, BN 2010. Çim alanlarda değișik tarımsal 
uygulamaların bitki gelişimi ve çim kalitesine etkileri. TÜBİTAK 1050584 nolu proje sonuç raporu.

Altan S 1989. Yer Örtücüler, Çukurova Üniversitesi Ziraat Fakültesi Ders Kitab1 No: 108, Adana.

Avcıoğlu R 1997. Çim Tekniği (Yeşil Alanların Ekimi, Dikimi ve Bakımı), Ege Üniversitesi Ziraat Fakültesi, Tarla Bitkileri Bölümü, Bornova-İzmir.

Beard J 1998. The origins of turfgrass species. Golf Course Management, 66(3), 49-55,

Bilgili U, Acikgoz E 2005. Year-round nitrogen fertilization effects on growth and quality of sports turf mixtures. J. Plant Nutri. 28:299-307.

Bilgili U, Acikgoz E 2011. Effects of slow-release fertilizers on turf quality in a turf mixture. Turkish Journal of Field Crops. 16: (2) 130-136.

Bilgili U, Topac-Sagban FO, Surer İ, Caliskan N, Uzun P, Acikgoz E 2011. Effects of wastewater sludge topdressing on color, quality, and clipping yield of a turfgrass mixture. HortScience: 1308-1313.

Brink GB, Rowe DE, Sistani KR 2002. Broilerlitter application effects on yield and nutrient uptake of'Alicia' bermudagrass. Agronomy Journal, 94, 911-916.

Burton GW, Hook JE, Butler JL, Hellwig RE 1988. Effect of temperature, daylength, and solar radiation on production of Coastal bermudagrass. Agron J 1988;80:557-60.

Cemek B, Apan M, Kara T, Taşan M 2004. Sera Koşullarında A-Sınıfı Buharlaşma Kabı ve Küçük Buharlaşma Kaplarından Buharlaşan Su Miktarı Arasındaki İlişkiler. Uludag.Üniv.Zir.Fak.Derg., 8(2): $13-24$

Christians N 2004. Fundamentals of Turfgrass Management. John Wiley and Sons, NJ, USA, 359 p.

Çöpür Z, Uysal S 2004. Çorum İl Çevre Durum Raporu. http://www.cedgm.gov.tr/icd raporlari/corumicd2003.pdf

Ekici ÖK 2011. Azot kirliliği ekosisteme zarar veriyor. Bilim Teknik Dergisi, Mayıs 522.

Emekli Y, Baştuğ R., Büyüktaş D, Emekli NY 2007. Evaluation of a crop water stress index for irrigation scheduling of bermudagrass. Agric. Water Manage. 90: $205-212$

Emmons R 1995. Turfgrass Science and Management. Delmar Publishing, Washington, USA, 512 p.

Emmons R 2000. Warm Season Grasses. Turfgrass science and management. 3rd Edition. Delmar Publishers, Albany, NY, USA.

Goatley JM, Maddox V, Lang DV, Crouse KK 1994. Tifgreen Bermudagrass response to late-season application of nitrogen and potassium. Agron. J. 86:7-10.

Mcbee GG, Holt EC 1966. Shade tolerance studies on bermudagrass and other turfgrasses. Agronomy Journal, 14-17,

Mehall BJ, Hull RJ, Skogley CR 1983. Cultivar Variationin Kentucky Bluegass: P and K Nutritional Factors. Agron. J. 75:767-772.

Moore RW, Christians NE, Agnew ML1996. Response of Three Kentucky Bluegrass Cultivars to Sprayable Nitrogen Fertilizer Programs. Crop Sci., 36:12961301.

Newman YC, Sinclair TR, Blount AS, Lugo ML, Valencia E 2007. Forage production of tropical grasses under extended daylength at subtropical and tropical latitudes. Environ Exp Bot, 61:18-24.

Nizam İ 2009. Azotlu Gübrelemenin Çokyıllık Çim (Lolium perenne L.)'in Tohum Verimi ve Bazı Bitkisel Özelliklerine Etkisi. Tekirdağ Ziraat Fakültesi Dergisi, Sayı 6 (2), Tekirdağ.

Orçun E 1979. Özel Bahçe Mimarisi (Çim Sahaları Tesis ve Bakım Tekniği). Ege Üniversitesi, Ziraat Fakültesi Yayınları Yayın No: 152, Bornova, İzmir,106 s.

Patton A, Boyd J 2007. Choosing a Grass for Arkansas Lawns, Agriculture and Natural Resources, Cooperative Extension Service, FSA2112.

Read J.J, Brink G.E, Oldham J.L, Kingery W.L. and Sistani K.R 2006. Effects of broiler litter andnitrogen fertilization on uptake of major nutrients byCoastal bermudagrass. Agronomy Journal, 98:065-1072.

Salisbury FB, Ross CW 1992. Plant Physiology, Wadsworth Pub. Com., Inc., Belmont, CaliforniaUSA.

Salman A 2008. Farklı Gübre Dozlarının Bazı Serin ve Sıcak İklim Çimlerinin Yeşil Alan Performanslarına Etkisi. Ege Üniver. Fen Bilimleri Enstitüsü (Doktora Tezi), Bornova-İzmir.

Sills MJ, Carrow RN 1983. Turfgrass growth, N use and water use under soil compaction and $\mathrm{N}$ fertilization. Argon. J.,75: 488-492.

Trenholm LE, Unruh JB 2007. Seashore Paspalum for FloridaLawns, http://edis.ifas.ufl.edu/EP059.

Trenholm LE, Unruh, JB, Cisar JL 2007. Selecting a Turfgrass for Florida Lawns, University of Florida, Ifas Extension ENH04, Florida, USA.

Wehner, DJ, Haley JE, Martın DL 1988. Late Fall Fertilization of Kentucky Bluegrass. Agron. J., 80: 466471. 